\title{
Pathways to parental anxiety: effect of coping strategies for disruptive behaviors in children with attention deficit-hyperactivity disorder
}

\author{
Napakkawat Buathong*, Nuttorn Pityaratstian, Apittha Unahalekhaka
}

\begin{abstract}
Background: Disruptive behaviors are commonly found in children with attention deficit-hyperactivity disorder (ADHD) and affect the mental health of parents. However, a study of the direct and indirect effects between disruptive behaviors in children with ADHD and parental anxiety and coping strategies is apparently lacking.

Objective: To examine the direct and indirect relationship between disruptive behaviors in children with ADHD and parental anxiety and coping strategies as a mediator.

Method: A cross-sectional study was conducted at King Chulalongkorn Memorial Hospital, Thailand between March 2015 and January 2016. Participants comprised 200 parents whose children were diagnosed with ADHD by physicians. Participants completed questionnaires regarding sociodemographic characteristics including The Thai Hospital Anxiety and Depression Scale, The Swanson, Nolan and Pelham (SNAP-IV): parent form (Thai version), and The Coping Scale Questionnaire (Thai version).

Results: The direct path between disruptive behaviors and anxiety was significant $(b=0.21, P=0.002)$. Moreover, a significant indirect path was found between disruptive behaviors and coping behavior with escape-avoidance $(\beta=0.20, P=0.005)$, and an indirect path was found between escape-avoidance and anxiety $(\mathrm{b}=0.31, P<0.001)$.

Conclusions: Health care professionals should evaluate the use of coping strategies by parents of children with ADHD and encourage the parents to use a positive strategy for coping with the disruptive behaviors of their children.
\end{abstract}

Keywords: attention deficit disorder with hyperactivity; disruptive behavior; parental anxiety

Attention deficit-hyperactivity disorder (ADHD) is one of the most common neurodevelopmental disabilities, characterized by disruptive behaviors such as hyperactivity, inattention, impulse control, and behavioral disinhibition $[1,2]$. Parents of children with neurodevelopmental disorders are at risk for parental stress and mental health problems [3-5]. Children with ADHD have lower adaptive function and interpersonal relationship problems with peers, siblings, and parents that result in symptoms of anxiety or depression in parents [6-9]. Several factors that influence parental anxiety include parental education, financial stressors, socioeconomic status, social support, spousal support, and coping strategies used to face stressful situations $[10,11]$.

Coping strategies can be defined as the adaptation of an individual to stressful events or situations involving cognitive, emotional, and behavioral efforts intended to reduce stress and

*Correspondence to: Napakkawat Buathong, (present address) Kids and Youth Development Research Unit, Department of Family Medicine and Preventive Medicine, Faculty of Medicine, Prince of Songkla University, Hat Yai, Songkhla, 90110, Thailand, e-mail: napakkawat.b@psu.ac.th Department of Psychiatry, Faculty of Medicine, Chulalongkorn University, Bangkok 10330, Thailand

D Open Access. ๑ 2019 Napakkawat Buathong et al., published by Sciendo. (c) Br-NC-ND This work is licensed under the Creative Commons Attribution NonCommercial-NoDerivatives 4.0 License. 
manage negative emotions [12]. There are 2 types of coping strategies: (1) adaptive coping methods including information seeking and (2) problem-solving and palliative-coping methods such as denial or escape-avoidance [13]. Palliative or poor coping strategies used by the mother or father of children with ADHD may lead to increased anxiety $[14,15]$.

Several studies show that disruptive behaviors in children with ADHD negatively impact parental mental health. However, a study of the direct and indirect relationship between disruptive behaviors in children with ADHD and parental anxiety by coping strategies as a mediator is apparently lacking. We hypothesized that disruptive behaviors in children with ADHD should directly affect parental anxiety, that coping strategies would mediate the association between disruptive behaviors in children with ADHD and parental anxiety, and that coping strategies with escape-avoidance are associated with increased parental anxiety.

\section{Materials and methods}

A cross-sectional study was conducted between February 2015 and January 2016 at King Chulalongkorn Memorial Hospital, a public general and tertiary referral teaching hospital with approximately 1,500 beds in Bangkok, Thailand. We selected 200 participants purposively based on inclusion and exclusion criteria. The inclusion criteria for the participants (who were parents or primary carers) were that parenting time with their child must be more than $12 \mathrm{~h}$ per day, their child was diagnosed with ADHD by a child psychiatrist, and their willingness to participate in our study. The exclusion criteria were children with ADHD and a comorbidity of autism, intellectual disabilities, and conduct disorder. This study was approved by the Ethics Committee and Institution Review Board of the Faculty of Medicine, Chulalongkorn University (approval No. 042/2015) following the principles of the Declaration of Helsinki and its contemporary amendments. All participants provided their written informed consent to participate in our study.

All participants responded to questions in self-rating questionnaires about their sociodemographic factors including sex, age, education, employment, financial difficulties or inadequate income, number of children and relationship to the child, and information about the child including its medical history. The Swanson, Nolan and Pelham (SNAP-IV): parent form (Thai Version) is composed of 24 items (each item score $0-3)$ related to disruptive behaviors of the child with ADHD, including inattentive, hyperactive-impulsive, and oppositional defiant subtypes. The SNAP-IV: parent form (Thai version) has shown good internal consistency with a Cronbach's $\alpha$ coefficient of 0.93-0.96 [16]. The Thai Hospital Anxiety and Depression Scale (The Thai-HADS) is composed of 14 items (each item score 0-3) related to depressive symptoms and 7 items related to anxiety symptoms [17-19]. We used 7 items of the anxiety subscale to evaluate parental anxiety. A cutoff point of $\geq 11$ on the anxiety subscale was interpreted as a clinical anxiety. The sensitivity of anxiety subscale of the Thai HADS was $100 \%$, while the specificity was $86.0 \%$ for anxiety. The anxiety subscale also showed good internal consistencies with a Cronbach's $\alpha$ coefficient of 0.85 . The Coping Scale Questionnaire [20, 21] was adapted from the coping strategies questionnaire into Thai [22] to evaluate parental coping strategies when dealing with a recent difficult situation. The questionnaire consists of 56 items in 3 dimensions of coping strategies regarding planful problem solving, seeking of social support, and escape-avoidance. Each item was scored on a 5-point Likert-like scale. The highest score in 1 of the 3 dimensions indicated the preferred coping style. The reliability of the Thai version of the coping scale had good internal consistency with a Cronbach's $\alpha$ coefficient of 0.90 . To control information and recall bias regarding a child's disruptive behavior, parental anxiety, and parental coping strategies, participants responded to all questions using their experience within the previous month.

\section{Statistical analysis}

Categorical data were analyzed using descriptive statistics including frequency and percentages. The mean and standard deviation (SD) were used to describe these continuous variables. A bivariate analysis of the association between child disruptive behaviors, coping strategies, anxiety, and depression was conducted with a Pearson product-moment correlation coefficient using IBM SPSS Statistics for Windows (version 22.0). Structural equation modeling (SEM) path analysis was used to examine the direct and indirect effects of association within our hypothesized model. The maximum likelihood estimates of the model coefficients were obtained using AMOS (version 22.0). All acceptable models of fit included $\chi^{2}$ goodness-of-fit tests with $P<0.05$ indicating significance, comparative fit indices $(\mathrm{CFI}) \geq 0.90$, and root-mean-square error of approximation (RMSEA) $<0.05$ [23].

\section{Results}

The sociodemographic characteristics of the sample of 200 parents and their children are presented in Table 1. Most participants $(84.0 \%)$ were women aged between 26 and 70 years 
Table 1. Sociodemographic characteristics for parent and child $(N=200)$

\begin{tabular}{|c|c|c|c|}
\hline Parent & n (\%) & Child & n (\%) \\
\hline Relationship to child & & Sex & \\
\hline Mother & $168(84.0)$ & Male & $158(79.0)$ \\
\hline Age (mean: SD) & 43.4: 7.76 & Age (Mean: SD) & $11.2: 2.8$ \\
\hline Education & & Education & \\
\hline Primary school & $8(9.0)$ & Junior primary school & $52(26.0)$ \\
\hline Secondary school & $25(12.5)$ & Senior primary school & $63(31.5)$ \\
\hline College graduate & $34(17.0)$ & Junior high school & $65(32.5)$ \\
\hline Bachelor's degree or higher & $123(61.5)$ & Senior high school & $20(10.0)$ \\
\hline Employment & & Taking psychostimulant medication for ADHD & $185(92.5)$ \\
\hline Unemployed & $10(5.0)$ & & \\
\hline Employee & $86(43.0)$ & Drug holiday from psychostimulant medication & $120(60.0)$ \\
\hline Own business & $66(33.0)$ & & \\
\hline Government and state enterprise & $38(19.0)$ & Duration (years) of treatment (Median: IQR) & $3.63: 4.5$ \\
\hline Adequate income & $152(76.6)$ & $\begin{array}{l}\text { Number of disruptive behaviors } \\
\text { (Mean: SD); Range } 1.23: 1.11 ; 0-3\end{array}$ & \\
\hline $\begin{array}{l}\text { Number of children } \\
\text { (Mean: SD); Range } 1.89: 0.81 ; 1-5\end{array}$ & & Multiple symptoms of disruptive behaviors & \\
\hline Anxiety & $41(20.5)$ & Inattention & 79 (39.5) \\
\hline Coping strategies (Mean: SD) & & Hyperactivity-impulsivity & $84(42.0)$ \\
\hline Escape-avoidance 2.34: 0.57 & & Oppositional defiant behaviors & $84(42.0)$ \\
\hline Seeking of social support & 2.99: 0.81 & & \\
\hline Planful problem solving & 3.63: 0.51 & & \\
\hline
\end{tabular}

$\mathrm{IQR}$, interquartile range; SD, standard deviation

(mean $[\mathrm{SD}]=43.43$ [7.76]). Most of the participating parents hold a bachelor's degree or higher, and most are employed. About three-quarters of the participants reported an adequate income. The participants had from 1 to 5 children. The prevalence of anxiety among parents of children with ADHD was $20.5 \%$. A comparison of the most frequent coping strategies shows that the mean for the planful problem-solving strategy was higher than the mean for the seeking social support strategy and escape-avoidance strategy.

An examination of the demographic factors of children with ADHD shows that most were boys and that the average age of all children was 11 years. The education level of the children ranged from junior primary school to senior high school. Almost all children were taking psychostimulant medication and 60\% were allowed drug holidays from medication by physicians. The recent disruptive behaviors of each child reported by parents using SNAP-IV ranged from 0 to 3 symptoms. The multiple dimensions of disruptive behaviors among children were found to be inattention, hyperactivity-impulsivity, and oppositional defiant behaviors (Table 1).
We found multicollinearity between each type of disruptive behaviors (inattention, hyperactivity-impulsivity, and oppositional defiant behaviors). All types of disruptive behaviors were positively correlated with parental anxiety. Inattention was positively correlated with the seeking of social support for coping, while hyperactivity-impulsivity and oppositional defiant behaviors were positively correlated with the escape-avoidance coping strategy (Table 2).

Before conducting a structural equation model with path analysis, the association between the sociodemographic variables and anxiety was explored - we found no significant association.

Structural equation model: path analysis: The results of association between child behavior and parental anxiety, and coping strategies as mediators in the pathways of these associations are shown in Figures 1 and 2.

Model 1 (Figure 1) indicates an acceptable model fit with a $\chi^{2}$ test result of $0.05(P=0.82)$, a GFI of 0.99 , a CFI of 0.99 , and a RMSEA of 0.01 . Although the overall test indicates a good fit, significant direct paths were not found between inattention and anxiety $(\beta=0.09, P=0.28)$, 
Table 2. Bivariate correlations between disruptive behaviors, coping strategies, and parental anxiety

\begin{tabular}{|c|c|c|c|c|c|c|c|}
\hline & 1 & 2 & 3 & 4 & 5 & 6 & 7 \\
\hline Inattention & 1 & & & & & & \\
\hline Hyperactivity-impulsivity & $\begin{array}{c}r=0.50 \\
P<0.001\end{array}$ & 1 & & & & & \\
\hline Oppositional defiant & $\begin{array}{c}r=0.53 \\
P<0.001\end{array}$ & $\begin{array}{c}r=0.45 \\
P<0.001\end{array}$ & 1 & & & & \\
\hline Escape-avoidance & $\begin{array}{l}r=0.13 \\
P=0.07\end{array}$ & $\begin{array}{c}r=0.15 \\
P=0.037\end{array}$ & $\begin{array}{c}r=0.20 \\
P=0.005\end{array}$ & 1 & & & \\
\hline Seeking social support & $\begin{array}{c}r=0.19 \\
P=0.007\end{array}$ & $\begin{array}{c}r=0.00 \\
P=0.996\end{array}$ & $\begin{array}{c}r=0.08 \\
P=0.242\end{array}$ & $\begin{array}{c}r=0.21 \\
P=0.002\end{array}$ & 1 & & \\
\hline Planful problem solving & $\begin{array}{l}r=0.08 \\
P=0.28\end{array}$ & $\begin{array}{l}r=-0.06 \\
P=0.379\end{array}$ & $\begin{array}{c}r=-0.004 \\
P=0.954\end{array}$ & $\begin{array}{c}r=0.01 \\
P=0.884\end{array}$ & $\begin{array}{c}r=0.41 \\
P<0.001\end{array}$ & 1 & \\
\hline Anxiety & $\begin{array}{c}r=0.20 \\
P=0.004\end{array}$ & $\begin{array}{c}r=0.17 \\
P=0.015\end{array}$ & $\begin{array}{c}r=0.26 \\
P<0.001\end{array}$ & $\begin{array}{c}r=0.33 \\
P<0.001\end{array}$ & $\begin{array}{c}r=0.03 \\
P=0.644\end{array}$ & $\begin{array}{c}r=0.03 \\
P=0.717\end{array}$ & 1 \\
\hline
\end{tabular}

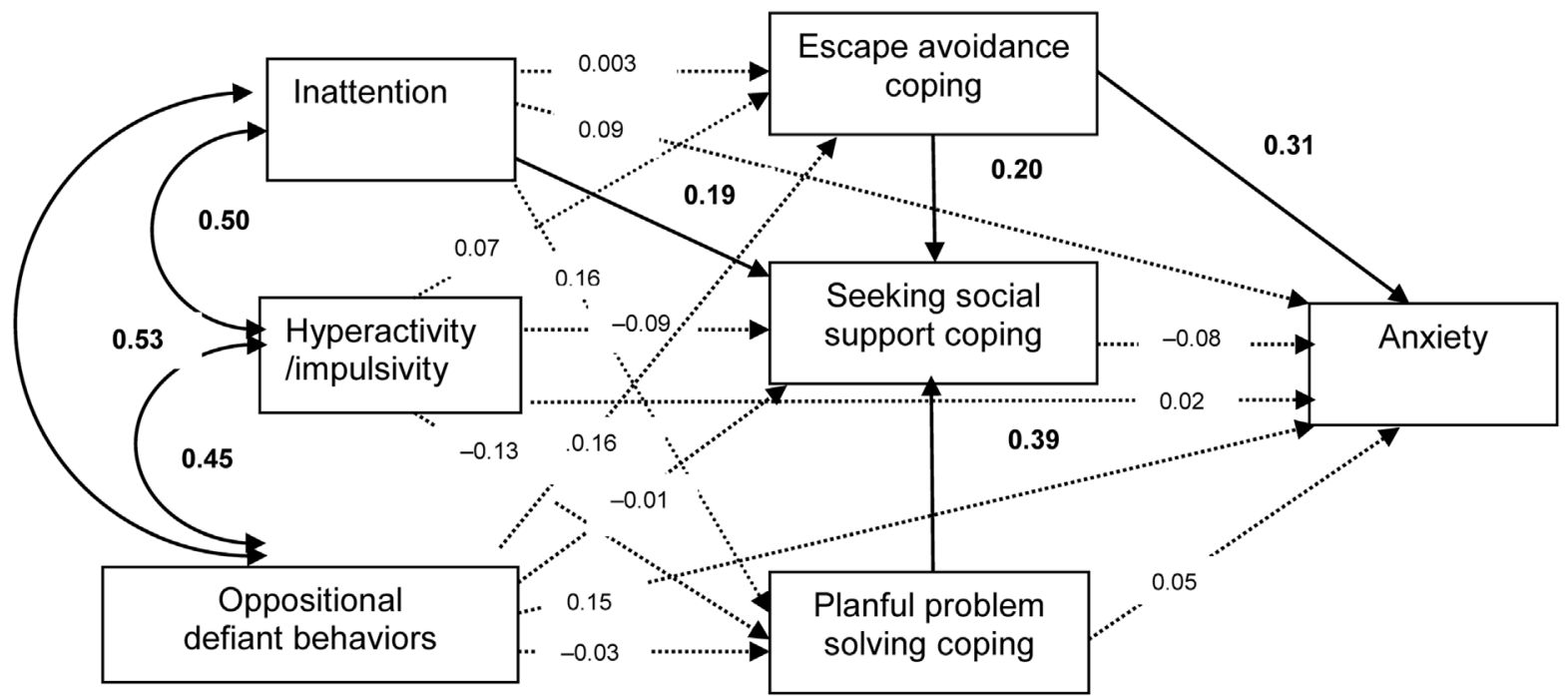

Figure 1. Coping strategies as mediators of inattention, hyperactivity-impulsivity, and oppositional defiant behaviors and anxiety $\left(X^{2}=0.05\right.$, $P=0.82, \mathrm{GFI}=0.99, \mathrm{CFI}=0.99, \mathrm{RMSEA}=0.01)$. Paths with solid lines and numbers in bold are significant $(P<0.05)$. All path coefficients are standardized

hyperactivity-impulsivity and anxiety $(\beta=0.02, P=0.82)$, and oppositional defiant behaviors and anxiety $(\beta=0.15, P$ $=0.06)$. The effects of multicollinearity between disruptive behaviors were determined as: inattention and hyperactivityimpulsivity $(\beta=0.50, P<0.001)$, inattention and oppositional defiant behaviors $(\beta=0.53, P<0.001)$, and hyperactivity-impulsivity and oppositional defiant behaviors $(\beta=$ $0.45, P<0.001)$. However, the indirect paths indicate that inattention significantly contributed to greater seeking of social support $(\beta=0.19, P=0.01)$, and coping with escapeavoidance is related to an increasing anxiety level. We also found an indirect path for the coping strategies association: coping with escape-avoidance leads to greater seeking of social support $(\beta=0.20, P=0.001)$, and planful problemsolving coping relates to greater seeking of social support ( $\beta=0.39, P=0.001)$.

In model 2 (Figure 2), we combined inattention, hyperactivity-impulsivity, and oppositional defiant behaviors scores to disruptive behavior scores. This final model has an acceptable model fit with a $\chi^{2}$ test result of $0.23(P=0.88)$, with GFI of 1.00, CFI of 1.00 , and the RMSEA of 0.00 . The direct path between disruptive behaviors and anxiety is significant $(\beta=0.21, P=0.002)$. Moreover, significant indirect paths between disruptive behaviors and coping with 


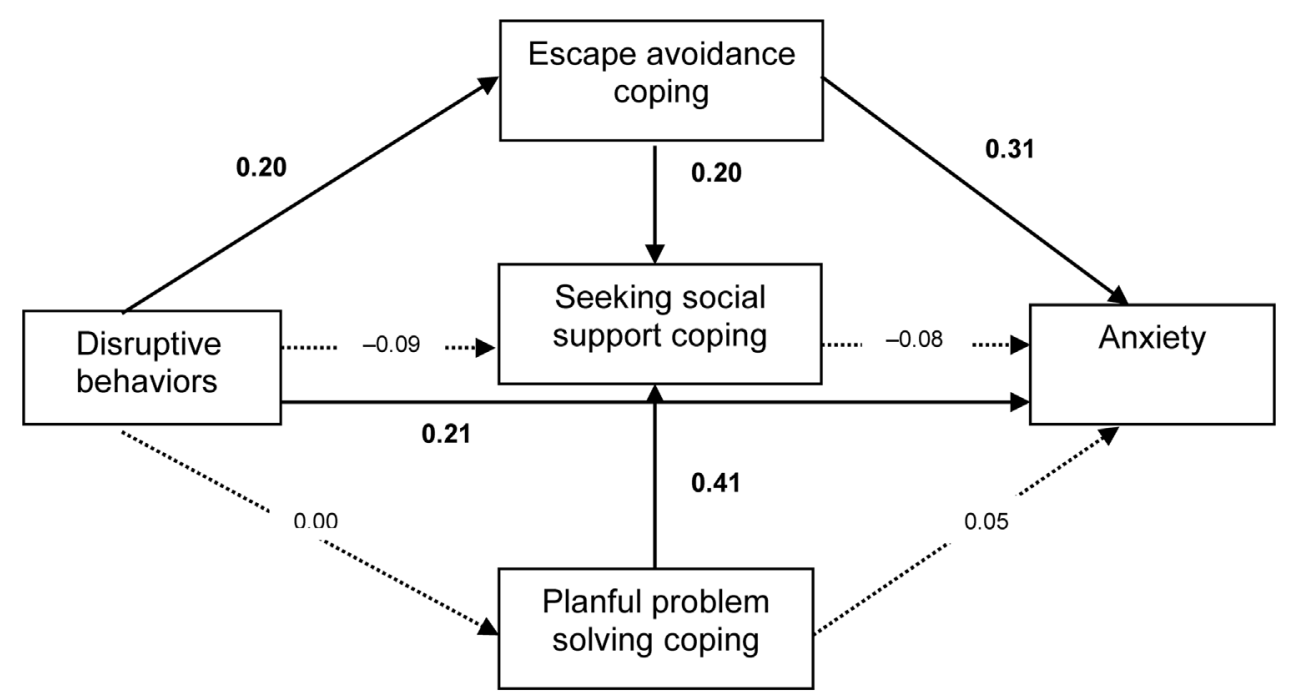

Figure 2. Final model of disruptive behaviors and coping strategies as mediators of anxiety $\left(X^{2}=0.23, P=0.88, \mathrm{CFI}=1.00, \mathrm{GFI}=1.00, \mathrm{RMSEA}=0.00\right)$. Paths with solid lines and numbers in bold are statistically significant $(P<0.05)$. Numbers in paths present the standardized regression coefficients

escape-avoidance $(\beta=0.20, P=0.005)$ and indirect paths between escape-avoidance and anxiety $(\beta=0.31, P<0.001)$ were found. Similarly, indirect paths between coping strategies were found for model 1. Specifically, coping with escapeavoidance relates to greater seeking of social support $(\beta=$ $0.20, P=0.002)$ and planful problem-solving coping relates to increased seeking for social support $(\beta=0.41, P<0.001)$.

\section{Discussion}

The present study examined pathways to parental anxiety related to coping strategies for disruptive behaviors in children with ADHD using a structural equation model. The hypothesized model was based on the reviewed literature, which indicated disruptive behaviors directly influence parental anxiety. Our initial findings support this hypothesis and indicate that disruptive behaviors of a child with ADHD should have a direct effect on parental anxiety. Increased inattention, hyperactivity-impulsivity, and oppositional defiant behavior scores were associated with an increase in parental anxiety. Others have found that the severity of a child's ADHD symptoms is associated with an increase in maternal and parental stress $[6,24]$. We found that a child's oppositional defiant traits have a stronger association with parental anxiety than a child's ADHD symptoms. This finding is consistent with that of previous studies that found that oppositional defiant, aggressive, and externalizing behaviors have often been found to be a stronger predictor of parental stress, anxiety, and depression than a child's ADHD symptoms $[6,25,26]$. This finding may have been influenced by the effects of ADHD psychostimulant medication on the children with ADHD - the medication may have reduced their inattentive and hyperactivity-impulsivity symptoms. As a high proportion of children with ADHD have co-occurring disorders, inattention, hyperactivity-impulsivity, and oppositional defiant behavior scores were combined into a "disruptive behavior" score, which was directly associated with the parental anxiety.

Our second hypothesis is based on Lazarus and Folkman's theoretical perspective on psychological stress and coping [12] that coping strategies mediate between stressful events and psychological outcomes. As predicted, escape-avoidance coping mediated the association between disruptive behaviors among children with ADHD and parental anxiety, while coping with seeking for social support and planful problem solving found no significant association with parental anxiety in our study.

Our findings are consistent with Lazarus and Folkman's theory [12] that escape-avoidance is an attempt to regulate negative emotions or distress when an individual perceives stressors as essential and unsolvable; consequently, this may cause mental health problems. This may reflect the findings that our participants are strained in dealing with their child's disruptive behaviors and use coping with escape-avoidance to reduce their stress. However, escape-avoidance has frequently been linked to the progression of anxiety level [15]. We also found significant correlations between coping with escapeavoidance and seeking of social support, and between coping with planful problem solving and seeking of social support. This suggests that parents with anxiety try to find other positive coping strategies to diminish their distress. 
There were some limitations to our study. We used only a parent report of SNAP-IV that might overestimate child's disruptive behaviors. We used a cross-sectional study that may not detect changes of anxiety level over time. Further prospective studies should be considered, and other psychological symptoms of children with ADHD and their parents should be evaluated.

\section{Conclusions}

It may be helpful for health care professionals to evaluate the use of coping strategies of parents with children who have ADHD and to encourage them to use planful problem solving to cope with the stress. Helping parents connect with a support network or offering them participation in a parenting support group may be a positive strategy to help them cope with the disruptive behaviors of their child with ADHD.

Author contributions. NB contributed substantially to the conception and design of this study. NP and AU collected, analyzed, and interpreted the data. NB drafted the manuscript, and NP and AU critical revised it. All authors approved the final version of the manuscript submitted and take responsibility for statements made in the published article.

Acknowledgments. This study was supported by Rachadapiseksompotch Fund, Chulalongkorn University (GDNS 58-019-30-005).

Conflicts of interest statement. The authors have each completed and submitted an International Committee of Medical Journal Editors Uniform Disclosure Form for Potential Conflicts of Interest. Neither of the authors has any potential conflicts of interest to disclose.

\section{References}

[1] Barkley RA. Deficient emotional self-regulation: a core of attention-deficit/hyperactivity disorder. J ADHD Relat Disord. 2010; 1:5-37.

[2] Spencer TJ, Biederman J, Mick E. Attention-deficit/hyperactivity disorder: diagnosis, lifespan, comorbidities, and neurobiology ambulatory pediatrics. Ambul Pediatr. 2007; 7(1 Suppl):73-81.

[3] Schieve LA, Blumberg SJ, Rice C, Visser SN, Boyle C. The relationship between autism and parental stress. Pediatrics. 2007; 119:114-21.

[4] Whalen CK, Henker B. The child with attention-deficit/ hyperactivity disorder in family contexts. In: Quay HC, Hogan AE, editors. Handbook of disruptive behavior disorders. New York: Kluwer; 1999, p. 139-55.
[5] Theule J, Wiener J, Rogers MA, Marton I. Predicting parenting stress in families of children with ADHD: parent and contextual factors. J Child Fam Stud. 2011; 20:640-7.

[6] Podolski CL, Nigg JT. Parent stress and coping in relation to child ADHD severity and associated child disruptive behavior problems. J Clin Psychol. 2001; 30:503-13.

[7] Rao PA, Beidel DC. The impact of children with high functioning autism on parental stress, sibling adjustment, and family functioning. Behav Modif. 2006; 33:437-51.

[8] Danforth JS, Barkley RA, Strokes TF. Observations of parentchild interactions with hyperactive children: research and clinical implications. Clin Psychol Rev. 1991; 11:703-27.

[9] Rezendes DL, Scarpa A. Association between parental anxiety/ depression and child behavior problems related to autism spectrum disorders: the roles of parenting stress and parenting self-efficacy. Autism Res Treat. 2011; 2011:395190.

[10] Hauser-Cram P, Warfield ME, Shonkoff JP, Krauss MW, Sayer A, Upshur CC. Children with disabilities: a longitudinal study of child development and parent well-being. Monogr Soc Res Child Dev. 2001; 66:1-114; discussion 115-26.

[11] Harrison C, Sofronoff K. ADHD and parental psychological distress: role of demographics, child behavioral characteristics, and parental cognitions. J Am Acad Child Adolesc Psychiatry. 2002; 41:703-11.

[12] Folkman S, Lazarus RS, Gruen RJ, DeLongis A. Appraisal, coping health status, and psychological symptoms. J Pers Soc Psychol. 1986; 50:571-9.

[13] Judge SL. Parental coping strategies and strengths in families of young children with disabilities. Fam Relat. 1998; 47:263-8.

[14] Shahbaz A, Hasan S. Psychological distress and copping strategies in mother of children with ADHD. Int J Sci Eng Res. 2017; 8:1007-12.

[15] Durukan I, Erdem M, Tufan E, Congologlu A, Yorbik O, Turkray T. Depression and anxiety levels and coping strategies used by mothers of children with ADHD: a preliminary study. J Psychiatry. 2008; 9:217-23.

[16] Bussing R, Fernandez M, Harwood M, Hou W, Garvan CW, Eyberg SM, Swanson JM. Parent and teacher SNAP-IV rating attention deficit hyperactivity disorder symptoms: psychometric properties and normative ratings from a school district sample. Assessment. 2008; 15:317-28.

[17] Nilchaikovit T, Lotrakul M, Phisansuthideth U. Development of Thai version of hospital anxiety and depression scale in cancer patients. J Thai Psych Assoc. 1996; 41:18-30. [in Thai, English abstract]

[18] Zigmond AS, Snaith RP. The hospital anxiety depression scale. Acta Psychiatr Scand. 1983; 67:361-70.

[19] Bjelland I, Dahl AA, Haug TT, Necelmann D. The validity of the hospital anxiety and depression scale. An updated literature review. Psychosom Res. 2002; 52:69-77.

[20] Carver CS, Scheier MF, Weintraub IK. Asserting coping strategies: a theoretically based approach. J Pers Soc Psychol. 1989; 56:267-83.

[21] Lazarus RS, Folkman S. Stress, appraisal, and coping. New York: Springer; 1984.

[22] Kotcharat S, Yongkittikul C. Relationship between parenting styles and self-directed behaviors of Thai adolescents. In: Sompoch I et al., editors. Proceedings of the East-West Psychological Science Research Center. 2002 November 29, Bangkok, Thailand. Bangkok: Faculty of Psychology, Chulalongkorn University; Proceedings of the East-West Psychological Science Research Center 2002; 2:47-60. [cited 2018 June]. Available from: https://docs.wixstatic.com/ugd/28a c01_474e3ef4eb074186a2ceac563eb21370.pdf [in Thai, English title] 
[23] Kline RB. Principles and practice of structural equation modeling. 4th ed. New York: Guilford; 2015.

[24] Vitanza SA, Guarnaccia CA. A model of psychological distress for mothers of children with attention deficit-hyperactivity disorder. J Child Fam Stud. 1999; 8:27-45.

[25] Costa NM, Weems CF, Pellerin K, Dalton R. Parenting stress and childhood psychopathology: an examination of specificity to internalizing and externalizing symptoms. J Psychopathol Behav Assess. 2006; 28:113-22.

[26] Kashdan TB, Jacob RG, Pelham WE, Lang AR, Hoza B, Blumenthal J, Gnagy EM. Depression and anxiety in parents of children with ADHD and varying levels of oppositional defiant behaviors: modeling relationships with family functioning. J Clin Child Adolesc Psychol. 2004; 33:169-81. 